\title{
Publisher Correction: The development of a case-based course on global engineering ethics in China
}

\author{
Rockwell F. Clancy ${ }^{1,2,3}$
}

Accepted: 23 December 2020 / Published online: 12January2021

(C) Springer Nature Switzerland AG 2021

\section{Publisher Correction: International Journal of Ethics Education https://doi.org/10.1007/s40889-020-00103-1}

Due to an error in typesetting the original publication of "The development of a casebased course on global engineering ethics in China" contained anonymized references in the article and reference list. The original article has been updated.

The publisher apologizes for the inconvenience caused.

Publisher's note Springer Nature remains neutral with regard to jurisdictional claims in published maps and institutional affiliations.

The online version of the original article can be found at https://doi.org/10.1007/s40889-020-00103-1

Rockwell F. Clancy

R.F.ClancyIII@tudelft.nl

1 University of Michigan-Shanghai Jiao Tong University Joint Institute, Shanghai Jiao Tong University, Longbin Building, 800 Dongchuan Road - Minhang District, Shanghai 200240, China

2 Institute of Social Cognition and Decision-Making, Shanghai Jiao Tong University, Shanghai, China

3 Department of Values, Technology, and Innovation, Faculty of Technology, Policy, and Management, Delft University of Technology, Jaffalaan 5, 2628 BX Delft, the Netherlands 